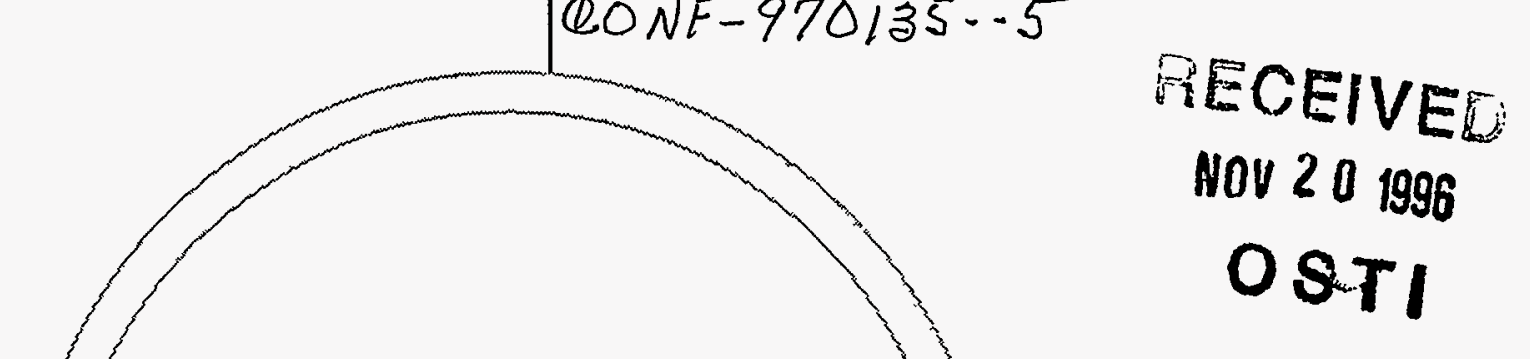

\title{
AN EXAMINATION OF LOADS AND \\ RESPONSES OF A WIND TURBINE \\ UNDERGOING VARIABLE-SPEED
}

OPERATION

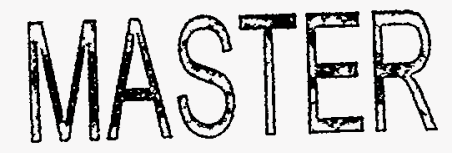

Alan D. Wright

Marshall L. Buhl, Jr.

Gunjit S. Bir

Prepared for

1997 ASME. Wind Energy Symposium

Reno, Nevada

January 6-9, 1997

\section{GN른}

National Renewable Energy Laboratory 1617 Cole Boulevard Golden, Colorado 80401-3393

A national laboratory of the U.S. Department of Energy Managed by Midwest Research Institute for the U.S. Department of Energy under contract No. DE-AC36-83CH10093

Work performed under task number WE618210 and WE619030

November 1996 


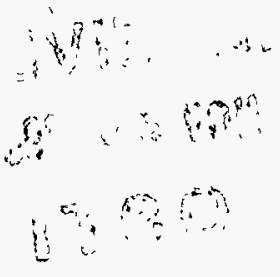

\section{NOTICE}

This report was prepared as an account of work sponsored by an agency of the United States government. Neither the United States government nor any agency thereof, nor any of their employees, makes any warranty, express or implied, or assumes any legal liability or responsibility for the accuracy, completeness, or usefulness of any information, apparatus, product, or process disclosed, or represents that its use would not infringe privately owned rights. Reference herein to any specific commercial product, process, or service by trade name, trademark, manufacturer, or otherwise does not necessarily constitute or imply its endorsement, recommendation, or favoring by the United States govemment or any agency thereof. The views and opinions of authors expressed herein do not necessarily state or reflect those of the United States government or any agency thereof.

Available to DOE and DOE contractors from:

Office of Scientific and Technical Information (OSTI)

P.O. Box 62

Oak Ridge, TN 37831

Prices available by calling (423) 576-8401

Available to the public from:

National Technical Information Service (NTIS)

U.S. Department of Commerce

5285 Port Royal Road

Springfield, VA 22161

(703) $487-4650$ 


\section{DISCLAIMER}

Portions of this document may be illegible in electronic image products. Images are produced from the best available original document. 


\title{
AN EXAMINATION OF LOADS AND RESPONSES OF A WIND TURBINE UNDERGOING VARIABLE-SPEED OPERATION
}

\author{
Alan D. Wright \\ Senior Engineer \\ Marshall L. Buhl, Jr. \\ Senior Mechanical Engineer \\ Gunjit S. Bir \\ Senior Mechanical Engineer \\ National Renewable Energy Laboratory \\ Golden, Colorado
}

\begin{abstract}
The National Renewable Energy Laboratory has recently developed the ability to predict turbine loads and responses for machines undergoing variable-speed operation. The wind industry has debated the potential benefits of operating wind turbines at variable speeds for some time. Turbine system dynamic responses (structural response, resonances, and component interactions) are an important consideration for variablespeed operation of wind turbines.
\end{abstract}

We have implemented simple, variable-speed control algorithms for both the FAST and ADAMS- dynamics codes. The control algorithm is a simple one, allowing the turbine to track the optimum power coefficient $\left(C_{p}\right)$.

The objective of this paper is to show turbine loads and responses for a particular two-bladed, teeteringhub, downwind turbine undergoing variable-speed operation. We want to see the response of the machine to various turbulent wind inflow conditions. In addition, we compare the structural responses under fixed-speed and variable-speed operation.

For this paper, we restrict our comparisons to those wind-speed ranges for which limiting power by some additional control strategy (blade pitch or aileron control, for example) is not necessary. The objective here is to develop a basic understanding of the differences in loads and responses between the fixed-speed and variable-speed operation of this wind turbine configuration.

- ADAMS is a registered trademark of Mechanical Dynamics, Inc. This paper is declared a work of the U.S. Government and is not subject to copyright protection in the United States.

\section{INTRODUCTION}

Major goals of the federal Wind Energy Program are to lower the cost of wind turbines and to increase their lifetime. In order to achieve these objectives, we may need to incorporate various control strategies in current wind turbine designs in order to mitigate damaging fatigue loads. We also need validated, structural simulators that incorporate these control schemes and allow us to evaluate their effects on dynamic loads and responses.

At the National Renewable Energy Laboratory (NREL), we are beginning to incorporate various control algorithms into some of our simulation codes. We are using the codes to evaluate the effects of various control strategies on system behavior and response. The simulation of the operation of a wind turbine using a particular control scheme for long periods is especially important. We want to input turbulent winds to the model and simulate at least 10 minutes of wind-turbine operation.

NREL has sponsored the development and validation of various codes for the prediction of wind-turbine loads and responses. A streamlined code is under development and refinement through a subcontract between NREL and Oregon State University. This code, called FAST (Fatigue, Aerodynamics, Structures, and Turbulence), can be used to model both two- and threebladed wind turbines. The two-bladed version is called FAST2 and the three-bladed version is called FAST3. The FAST codes model flexible bodies via modal coordinates and mode shapes. This is different from the multibody-dynamics approach used in ADAMS (Automatic Dynamic Analysis of Mechanical Systems) ${ }^{1}$, which models a flexible component by dividing it into a 
number of rigid body parts connected by springs. With FAST, a blade may be modeled with just a few degrees of freedom (DOF), such as two flap modes and one lag mode. This code is useful for simulating long run-times of the turbine when turbulent inflow is the main driver. For this paper, we have adapted the FAST2 code to include a simple control algorithm for variable-speed operation of a wind turbine.

In this paper we use the FAST2 code for modeling wind turbines operating with both fixed-speed and variable-speed controls. Our objective is to show turbine loads and responses for a particular, two-bladed, teetering-hub, downwind machine typical of some industry machines. We show a comparison of predicted loads and responses of the turbine operating both as a variable-speed and a fixed-speed machine. We do not actually make any comparisons with measured machine results in this paper; we show only predicted results. We realize that the final results will probably depend heavily on the particular control system being used by the actual wind turbine.

We investigate only briefly the subject of system resonances and the effect of critical rotor speeds on the excitation of operational modes, because this topic will require future detailed assessment. For this, we need tools that predict operational turbine modal characteristics and stability values, a capability not yet fully developed in the U.S. wind industry today.

In this paper, we give a brief description of the FAST2 code and the turbine being modeled. We describe very briefly the variable-speed control model as implemented in the FAST2 code. We then present the results of simulation of the turbine both under constant and variable rotor speed operation. We show these results for various wind speeds and discuss resulting predicted loads and responses. We next discuss the potential for mitigation of loads and responses by operating the turbine at variable rotor speed. We then draw conclusions and make recommendations for further work.

\section{CODE AND MODEL DESCRIPTION}

The FAST2 code models the dynamic response of a two-bladed, horizontal-axis wind turbine as six rigid bodies and four flexible bodies. The six rigid bodies are the earth, nacelle, tower-top base plate, armature, hub, and gears. The flexible bodies include blades, tower, and drive shaft. The model connects these bodies with several DOF. These include tower flexibility, rotor teeter, blade flexibility, nacelle yaw, rotor speed, and drive shaft torsional flexibility. The tower flexibility includes both side-to-side and fore-aft motion with two modes each. The blades have two flap modes per blade and one lag mode. These machine DOF can be turned on or off individually in the analysis by simply setting a switch in the input data file. For the results described in this paper, not all available DOF were active, as will be later described.

FAST uses Kane's method ${ }^{2}$ to set up equations of motion that can be solved by numerical integration. This method greatly simplifies the equations of motion by directly using the generalized coordinates and eliminating the need for separate constraint equations. These equations are easier to solve than those developed using the methods of Newton or Lagrange and have fewer terms, thus reducing computation time. For more information on FAST code theory and formulation, see Wilson. ${ }^{3}$

FAST uses Blade Element Momentum Theory to compute aerodynamic forces. At NREL, we are using two versions of FAST2: a version with the original Oregon State University aerodynamic subroutines and a version with the University of Utah AeroDyn subroutines. We set the goal of having the University of Utah develop a stand-alone aerodynamic subroutine package for inclusion into any wind turbine structural dynamics code. $^{45}$ This package includes the effects of dynamic stall, dynamic inflow, table look-up of $C_{l}$ and $C_{d}$ data, and input of 3-D turbulence. We have successfully incorporated the Utah AeroDyn subroutines into FAST and used this version for the results presented in this paper.

The machine we modeled in this study is a twobladed, teetering-hub, free-yaw, downwind turbine. The 12.1-m (39.7-ft) fixed-pitch blades have a $5.5^{\circ}$ pretwist with a maximum chord of $1.2 \mathrm{~m}(3.8 \mathrm{ft})$. They use the NREL thick airfoil family (S809, S810, and S815) designed for $12-\mathrm{m}(40-\mathrm{ft})$ blades. The blades have a $1.27^{\circ}$ pitch orientation toward feather (leading edge pitched into the wind).

The rotor diameter is $26.2 \mathrm{~m}$ ( $86 \mathrm{ft}$ ) with a $7^{\circ}$ precone. It sits on top of a free-standing tube tower, and the hub height is $24.4 \mathrm{~m}(80 \mathrm{ft})$. The machine generates $275 \mathrm{~kW}$ of power at rated wind speed $(18 \mathrm{~m} / \mathrm{s}, 40 \mathrm{mph})$. Each blade has a tip brake, which weighs approximately $11.3 \mathrm{~kg}(25 \mathrm{lb}$.).

For these studies, we included in our analysis the following turbine DOF: blade flap (first and second modes), rotor teeter, rotor rotation, nacelle yaw, and tower fore-aft and lateral bending (two modes each). We did not enable the blade's edgewise DOF for this study. In the aerodynamic load calculations, we included the effects of tower shadow (with a 50\% deficit factor); dynamic stall, and dynamic inflow. 
For this turbine configuration, we modeled the effects of nonlinear teeter dampers that engage at a $2^{\circ}$ teeter deflection. The damping forces are nonlinear functions of the teeter excursion.

We modeled the generator simply as an applied torque on the generator side of the low-speed shaft. We neglected drivetrain torsional effects. We also assumed perfect gearbox and generator efficiencies. We applied these same assumptions to both the fixed-speed (FS) and variable-speed (VS) configurations in order to make a valid comparison. We now describe the simple variable-speed control algorithm that we implemented in FAST2.

\section{VARIABLESPEED CONTROLALGORITHM}

A wind turbine is normally characterized by its $C_{p}$ versus tip-speed ratio (TSR) curve. Figure 1 shows such a curve for the machine modeled in this study. The power captured by a wind turbine is:

$$
P=\frac{1}{2} \rho A C_{p} V^{3}
$$

where:

$$
\begin{aligned}
& \rho \text { is the air density, } \\
& A \text { is the rotor swept area, } \\
& C_{p} \text { is the rotor power coefficient, and } \\
& V \text { is the free-stream wind speed. }
\end{aligned}
$$

From this equation, one can see that operating the system at maximum $C_{p}$ at all wind speeds will optimize the power production. One must keep the rotor speed at a target TSR to operate the wind turbine at a maximum $C_{p}$. Thus, as the wind speed changes, the rotor speed should follow this change. This is possible with a VS turbine, although reliable wind speed measurements are usually difficult or impossible to obtain. To avoid using wind speed to control the generator, one can modify the equation for target power to eliminate dependence on wind speed:

$$
P_{\text {rarg }}=K \Omega^{3}
$$

where:

$$
K=\frac{1}{2} \rho A C_{p_{\text {tars }}}\left(\frac{R}{\lambda_{\text {targ }}}\right)
$$

$P_{\text {larg }}$ is the target power,

$C_{p . t a r g}$ is the target power coefficient,

$\lambda_{\text {targ }}$ is the target TSR,

$R$ is the rotor radius, and

$\Omega$ is the rotor speed.

For more details see Muljadi. ${ }^{6}$

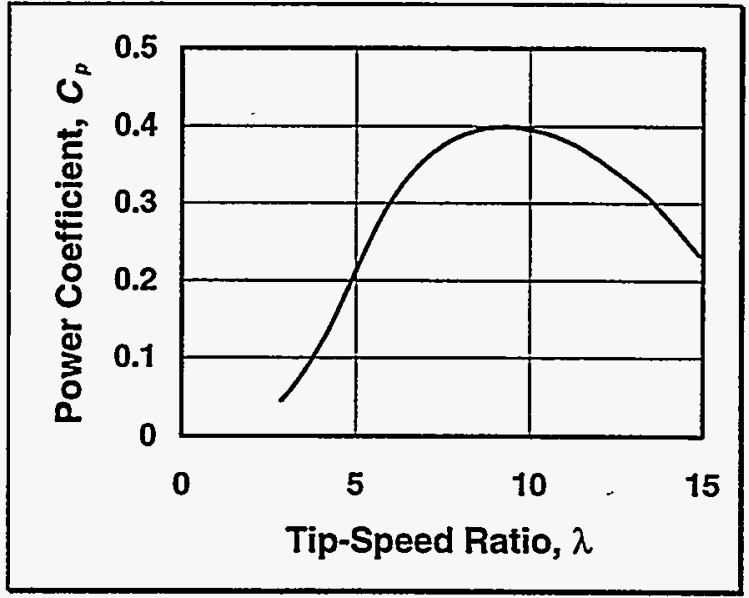

Figure 1. $C_{p}$ versus tip-speed ratio.

The torque can be expressed as:

$$
T_{\text {targ }}=K \Omega^{2}
$$

where $T_{\text {arg }}$ is the applied torque. We implemented this expression in FAST2 for the torque applied to the low-speed shaft. We assume no knowledge of wind speed, but do assume that we know rotor speed at each time step. The applied torque is simply a constant multiplied by the square of rotor speed. We chose a $C_{\text {p.targ }}$ of 0.4 and a $\lambda_{\text {targ }}$ of 8.8 , from examination of the $C_{p}-\lambda$ curve shown in Figure 1 .

Theoretically, the power generated is unlimited and is a function of wind speed cubed. Realistically, there are mechanical and electrical factors that put limits on the turbine's power. Usually there will be a rotor speed limit and a power limit. The generator used will have an upper speed limit based on its mechanical design. Also, the electrical components comprising the generator circuit will have a power limit.

For this study we imposed no limits on rotor speed or power. Such control schemes are the topic of future studies. We restricted our study to cases in which large power excursions did not occur. As a result, we used wind inflow data sets with average wind speeds of 6 to $10 \mathrm{~m} / \mathrm{s}$.

\section{WIND INFLOW CONDITIONS}

Kelley's SNLWIND-3D ${ }^{7}$ turbulence-simulation code generated the turbulent wind files for each of the three case studies. This code is an expansion of the SNLWIND $^{8}$ code developed by Veers for simulating the longitudinal component of the inflow. In contrast to Veers' original version, SNLWIND-3D generates the full wind vector in Cartesian space and provides a wide range of turbulence conditions. These include 
conditions seen over smooth, homogeneous terrain; at the upwind row of a multirow wind park; and within the wind park at various row spacings. The code also provides simulations using either the Kaimal or von Karman neutral-flow spectral models specified in the International Electrotechnical Commission (IEC) document on safety requirements for wind turbines.' In this study, we generated simulated inflows with the characteristics shown in Table 1.

Table 1. Characteristics of Inflow Cases

\begin{tabular}{|c|c|c|}
\hline Case & $\begin{array}{c}\text { Mean Horizontal } \\
\text { Wind Speed } \\
(\mathrm{m} / \mathrm{s})\end{array}$ & $\begin{array}{c}\text { Standard } \\
\text { Deviation } \\
(\mathrm{m} / \mathrm{s})\end{array}$ \\
\hline 6 & 6.20 & 0.988 \\
\hline 8 & 8.27 & 1.570 \\
\hline 10 & 10.30 & 1.830 \\
\hline
\end{tabular}

\section{COMPARISONS OF RESULTS}

For these cases we ran both the FS turbine and the VS turbine for the three turbulent inflow cases. For most of the results presented in this paper, we show probability densities (PDs) and statistics, rather than actual time series data, to consolidate and clarify the results. We calculated PDs from the code predictions using $\mathrm{GPP}^{10}$ (General-Purpose Postprocessor). We show PDs of the three wind-speed time series in Figure 2. The PDs for the higher wind speed cases become broader and shallower, indicating higher standard deviations. The lowest wind speed case clusters around $6 \mathrm{~m} / \mathrm{s}$ and is tall and narrow compared to the other two cases.

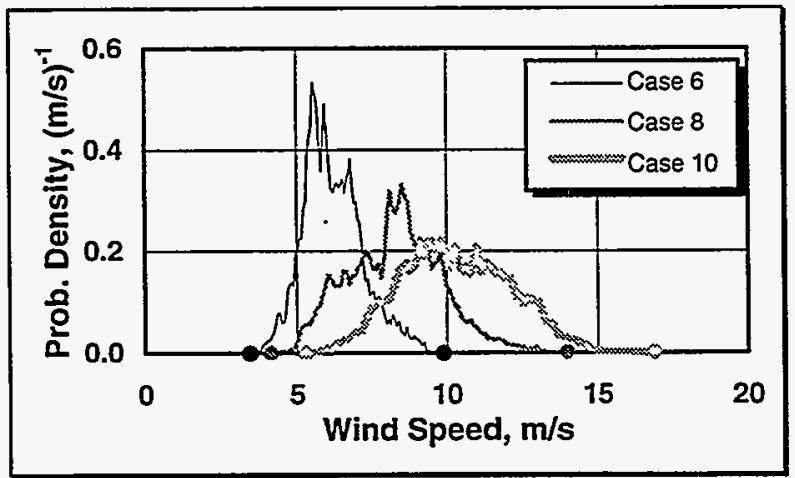

Figure 2. Wind-speed probability densities

In Figure 3, we show the rotor speed PDs for the VS turbine. Table 2 shows statistics for major turbine parameters discussed in this study. Generally, the PDs of rotor speed follow the same trend as those for the wind speed, with tall and narrow PDs for the lower wind speeds, indicating smaller standard deviations. Not

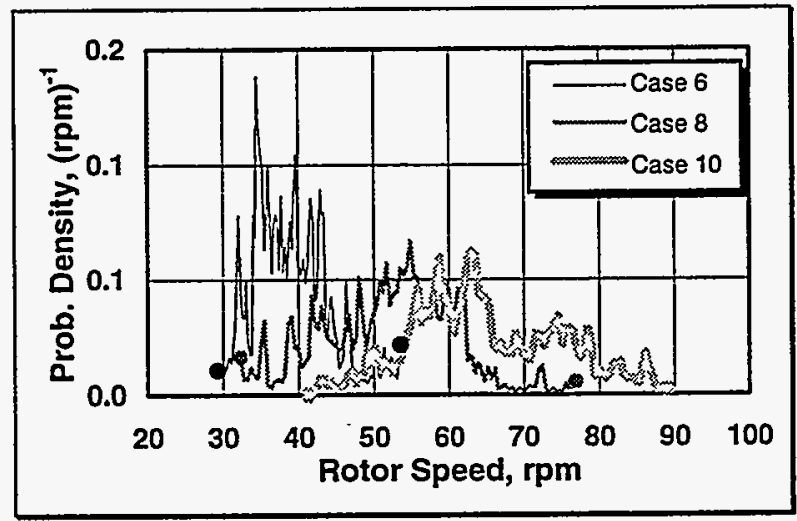

Figure 3. Rotor-speed probability densities

shown in Figure 3 is the PD of the FS case, which is very tall and narrow; the induction generator allows little variation in slip.

We calculated the rotor's $C_{p}$ (power coefficient due to aerodynamic torque only) and show PDs for the FS machine versus the VS machine for all three wind speed sets, seen in Figure 4. We note that for Case 6, the VS machine maintains a PD centered about the target $C_{p}$ of 0.4 , while the FS machine clusters about a lower value and is much broader. The VS machine is attempting to

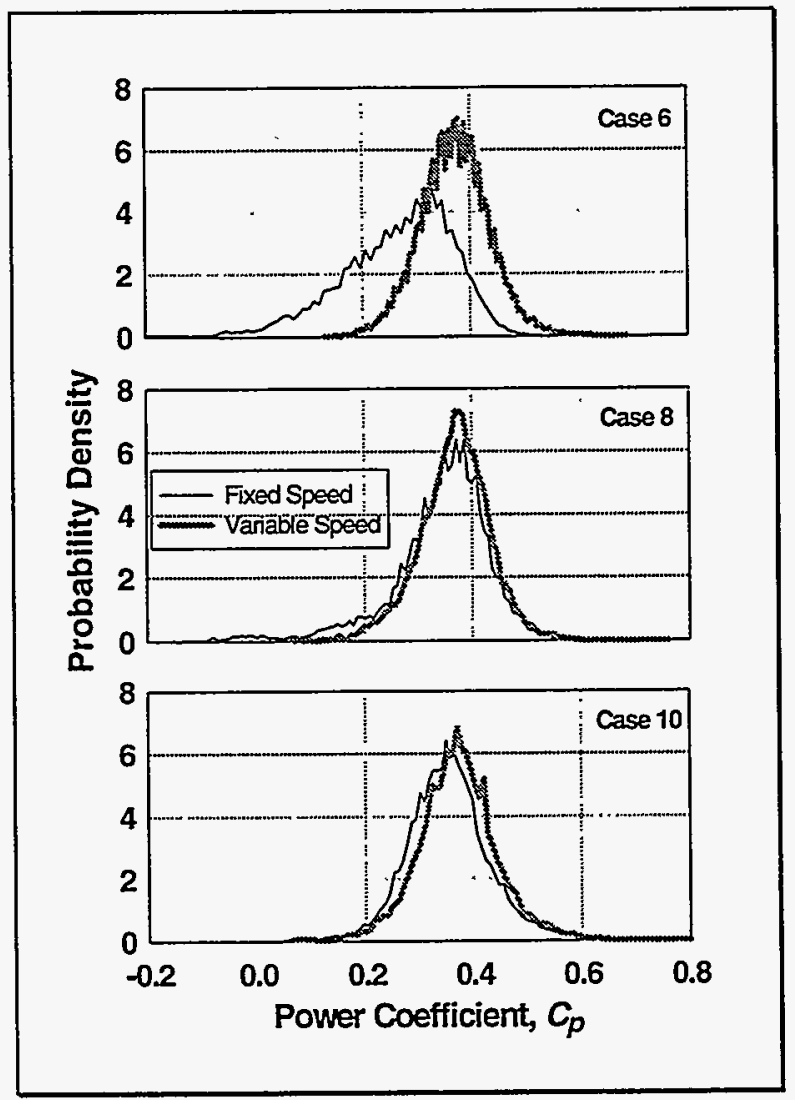

Figure 4. Probability densities of rotor $C_{p}$ 
Table 2. Turbine Parameter Statistics (Mean and Standard Deviation)

\begin{tabular}{|c|c|c|c|c|c|c|}
\hline Case & $\begin{array}{c}\text { Rotor Speed } \\
(\mathbf{r p m})\end{array}$ & Rotor $\mathrm{C}_{\mathbf{p}}$ & $\begin{array}{c}\text { Rotor Torque } \\
(\mathrm{kN} \mathrm{m})\end{array}$ & $\begin{array}{c}\text { Rotor Power } \\
(\mathbf{k W})\end{array}$ & $\begin{array}{c}\text { Flap } \\
(\mathbf{k N ~ m})\end{array}$ & $\begin{array}{c}\text { Rotor Teeter } \\
\text { (degrees) }\end{array}$ \\
\hline \multirow{2}{*}{ 6, VS } & 39.1 & 0.37 & 6.4 & 27.3 & -2.4 & 0.00 \\
& 5.2 & 0.06 & 1.7 & 13.4 & 3.6 & 0.77 \\
\hline \multirow{2}{*}{ 6, FS } & 57.5 & 0.26 & 3.6 & 22.0 & -27.3 & 0.00 \\
& 0.1 & 0.11 & 2.6 & 15.9 & 7.5 & 0.43 \\
\hline \multirow{2}{*}{ 8, VS } & 51.9 & 0.37 & 11.4 & 66.1 & -4.1 & 0.00 \\
& 8.8 & 0.07 & 3.8 & 36.7 & 6.0 & 0.74 \\
\hline \multirow{2}{*}{ 8, FS } & 57.7 & 0.34 & 10.5 & 63.9 & -12.0 & 0.00 \\
& 0.1 & 0.09 & 6.1 & 36.9 & 12.3 & 0.62 \\
\hline \multirow{2}{*}{ 10, VS } & 64.8 & 0.37 & 17.7 & 127.0 & -6.2 & 0.00 \\
& 9.9 & 0.08 & 5.4 & 65.4 & 8.8 & 0.77 \\
\hline \multirow{2}{*}{ 10, FS } & 57.8 & 0.35 & 19.2 & 116.0 & 2.5 & 0.00 \\
& 0.1 & 0.08 & 8.2 & 50.5 & 12.9 & 0.83 \\
\hline
\end{tabular}

maintain the target $C_{p}$ value. For the higher wind speed cases, the differences between the FS and VS machines diminish, becoming almost identical for the $10 \mathrm{~m} / \mathrm{s}$ case. This type of machine usually has an optimum $C_{p}$ at a rotor speed of about 50-60 rpm for a moderate wind speed of about $10 \mathrm{~m} / \mathrm{s}$. At lower wind speeds, the VS turbine maintains a more optimal $C_{p}$ than the FS machine.

Figure 5 shows a plot of rotor torque PDs. Generally, we see a taller and narrower PD for the VS machine than for the FS machine. The time series plots (not shown here) for rotor torque show that the VS turbine exhibits a smoother characteristic with smaller extremes than the FS turbine. All wind speed cases showed this trend as is seen in the PDs. For Case 10, the mean values of rotor torque are about the same for both the VS and FS machines, although the standard deviations are less for VS.

We see PDs for the rotor's aerodynamic power in Figure 6. For Case 6, the PD of the VS rotor is similar to that of the FS rotor. For the higher wind speed cases, the VS machine reaches higher extremes than the FS turbine. For Case 10, we are exceeding the rated power of the turbine $(280 \mathrm{~kW})$, even reaching values almost up to $400 \mathrm{~kW}$.

Figure 7 shows PDs of the blade's flapwise bending moments for the various cases. These moments are the out-of-plane moments and do not necessarily align with the blade chord. These results show some load mitigation potential by operating the rotor as a VS machine over these wind-speed ranges. For the lowest wind speed case, the FS rotor attains larger negative values than the VS machine. Due to the rotor's precone angle $\left(7^{\circ}\right)$, centrifugal effects dominate the blade's root flapwise bending moments at low wind speed and high rotor speed. Positive bending moments bend the blade downwind, indicating dominance by aerodynamic loads. Negative bending moments come from centrifugal forces, and tend to bend the blade towards the plane of rotor rotation.

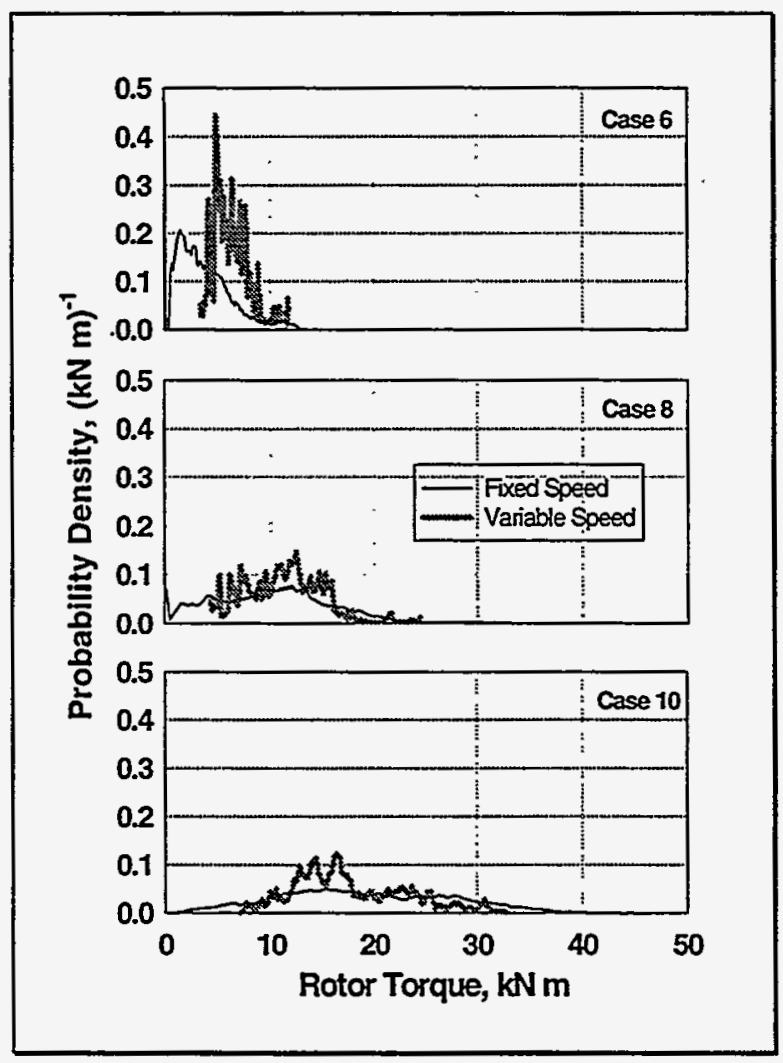

Figure 5. Probability densities of rotor torque. 


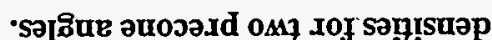

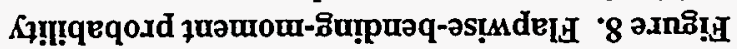

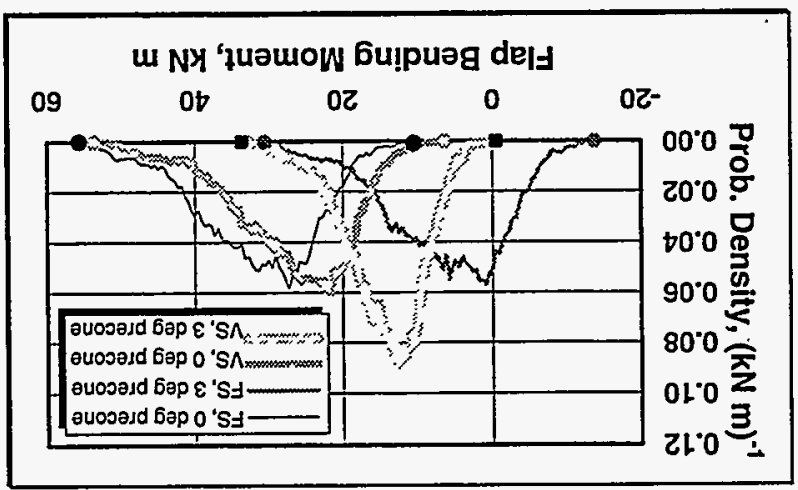

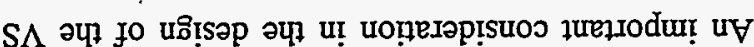

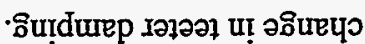

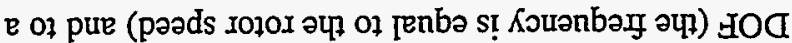

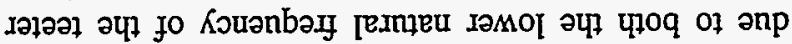
әq p!no s!̣L :

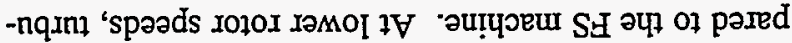

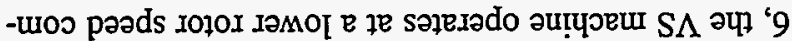

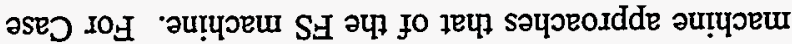

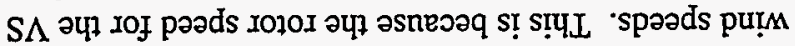

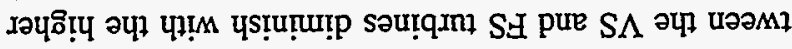

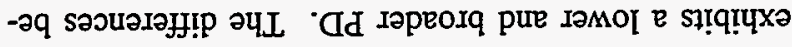

-อิu!̣parg

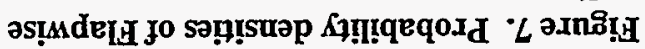

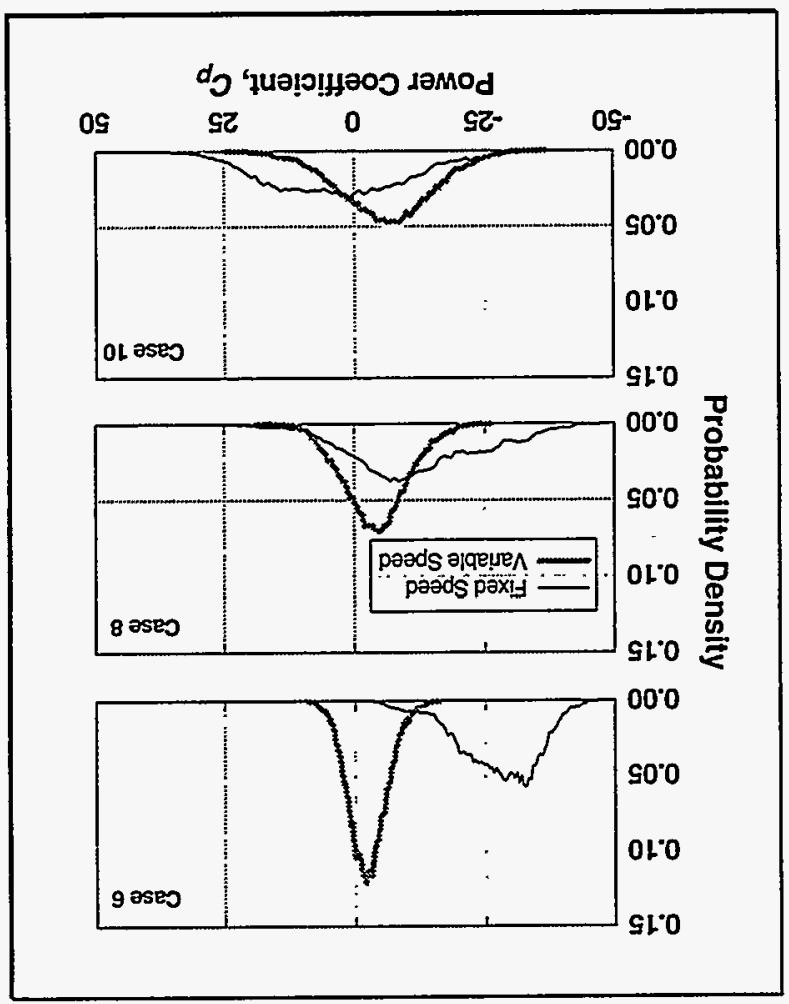

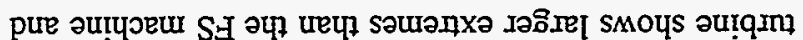

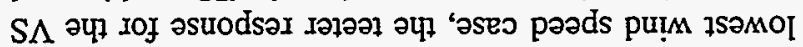

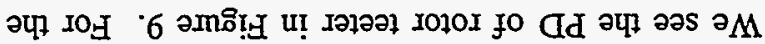

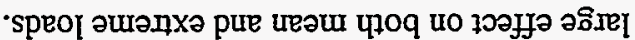

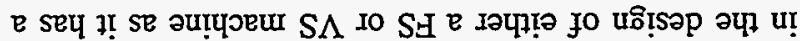

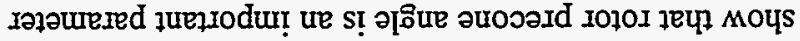

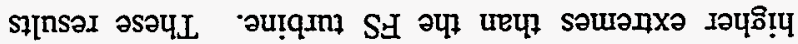

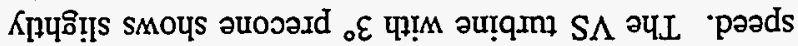

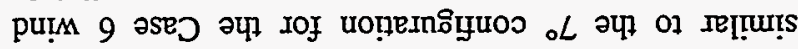

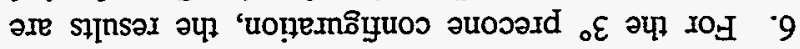

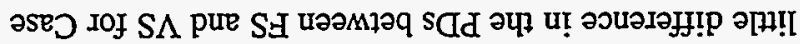

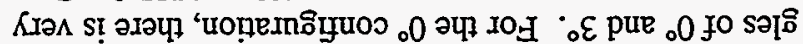

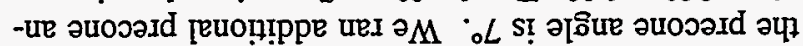

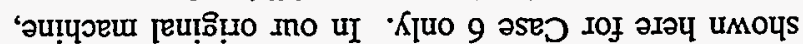
'วuоoəə⿱亠

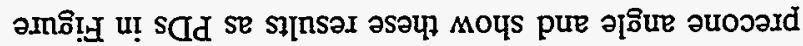

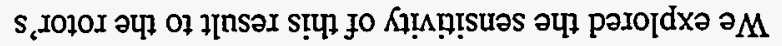

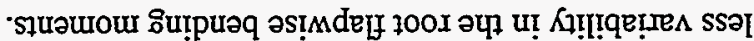

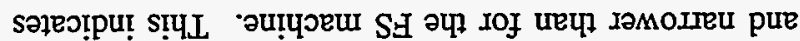

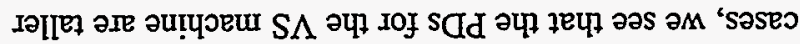

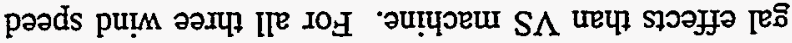

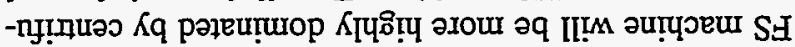

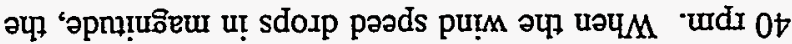

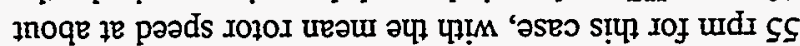
ol $0 E$ woy sәtุe

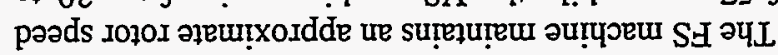

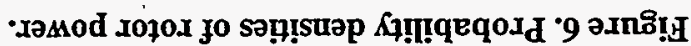

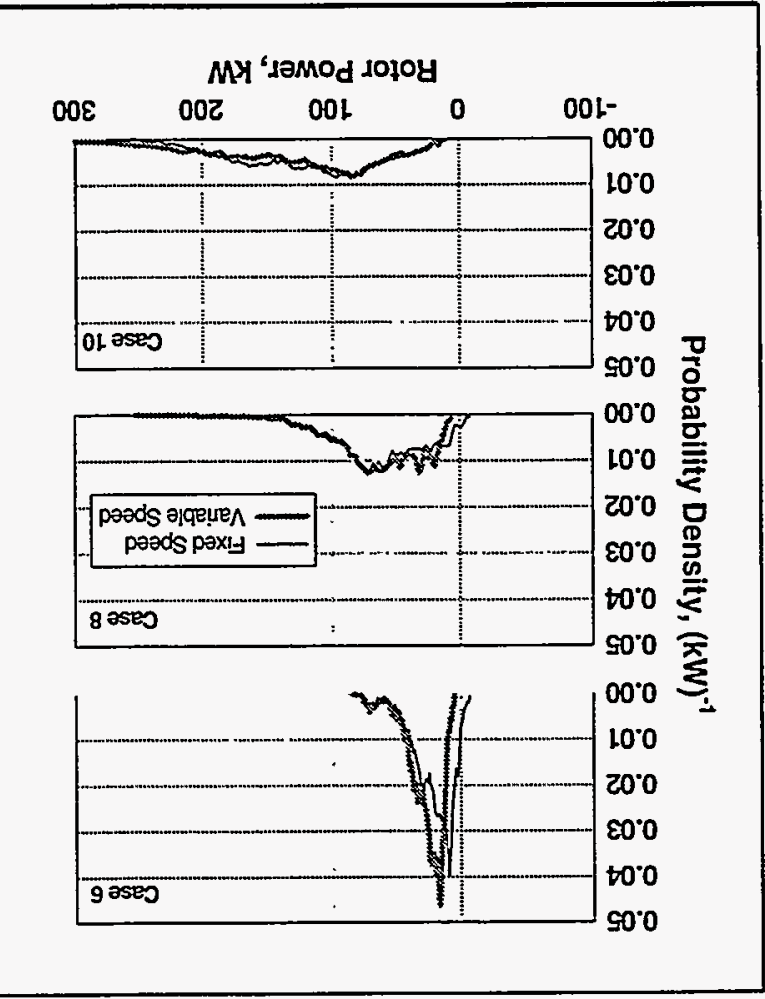




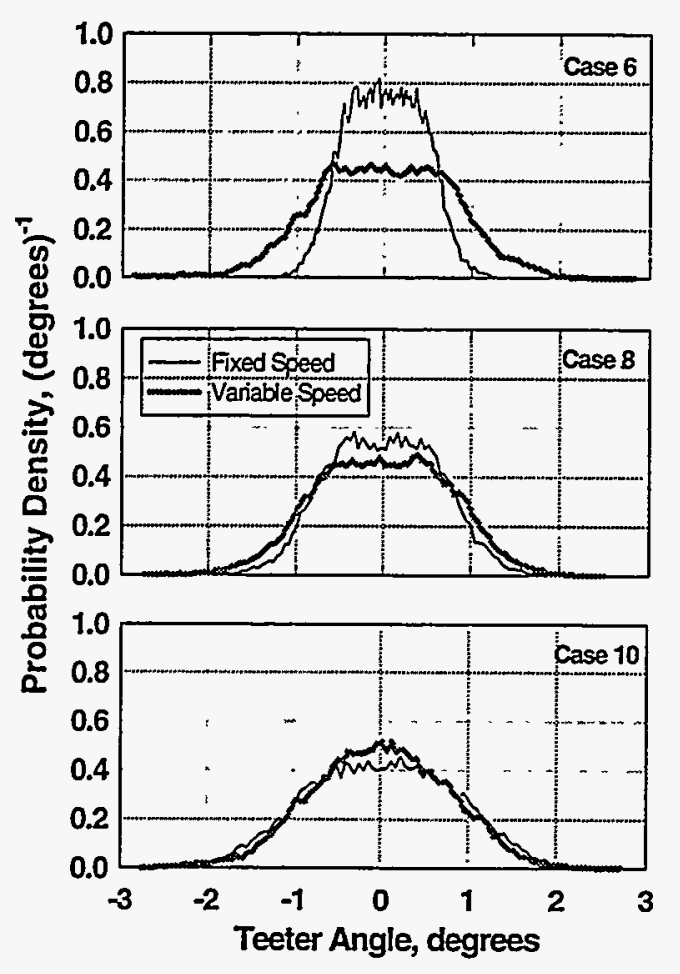

Figure 9. Probability densities of Rotor Teeter.

machine will be larger teeter responses at lower rotor speeds than for a FS machine. Another important consideration will be the introduction of teeter dampers. We created nonlinear models of teeter dampers that engage at $2^{\circ}$ of deflection. We also re-ran the Case 6 results with the teeter dampers turned off and found no big changes in either the teeter response trends or the flapwise bending moment trends previously described. For operation of a VS machine at low wind speeds and rotor speeds, the teeter dampers must be carefully designed to mitigate unwanted teeter excursions.

\section{CONSIDERATION OF TURBINE RESONANCES}

We made only a preliminary study of the effect of operating the VS machine at or close to those rotor speeds that might excite the natural modes of the machine. We confined our investigation to the excitation of the rotor's symmetric flapwise bending modes. To begin an examination of these effects, we looked at the VS machine's predicted rotor speeds for the three wind speed cases that we made with FAST2. We focused our examination to very short duration events in which we thought a particular rotor-speed harmonic coincided with one of these natural frequencies. We then looked at the corresponding flapwise bending moments at that same time.
Figure 10 shows a Campbell plot of the rotor's first and second symmetric flapwise natural frequencies. The variation of these frequencies with rotor speed is due to centrifugal stiffening.

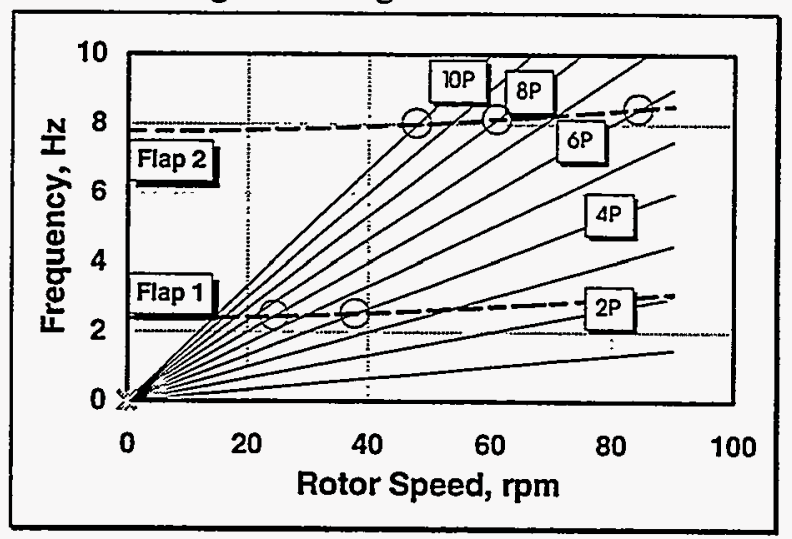

Figure 10. Campbell Plot.

We have shown in previous papers ${ }^{11}$ that the rotor's symmetric flap modes are highly excited if they lie at integer multiples of the rotor's rotational speed. This is especially true for two-bladed rotors at even harmonics (for example, $2 \mathrm{P}, 4 \mathrm{P}$, and $6 \mathrm{P})^{\circ}$. We thus examined those time series data produced by a FAST2 run in which the rotor's first and second symmetric flap frequencies coincided with these harmonics. As can be seen from the Campbell plot, the second flap natural frequency intersects the $10 \mathrm{P}, 8 \mathrm{P}$, and $6 \mathrm{P}$ harmonics at rotor speeds of 48,61 , and $84 \mathrm{rpm}$, respectively. In addition, the first flap frequency intersects the $6 \mathrm{P}$ and $4 \mathrm{P}$ harmonics at rotor speeds of 24 and $38 \mathrm{rpm}$, respectively.

We did not see too much excitation of the rotor's second flapwise mode at $45 \mathrm{rpm}$ (at 10P). Of greater significance was the excitation of the rotor's second flapwise mode at 8P, at rotor speeds in the range of 55$60 \mathrm{rpm}$. Figure 11 shows a plot of the root flapwise bending moment for one revolution at this rotational speed. The conditions for this event were a wind speed of $9.5 \mathrm{~m} / \mathrm{s}$ and a rotations rate of $60 \mathrm{rpm}$. The plot shows a substantial $8 \mathrm{P}$ harmonic content in this signal. For the FS machine, its $57.5 \mathrm{rpm}$ rotational speed will excite this mode continuously.

Of greater significance was excitation of the first symmetric flapwise mode at the high rotor speeds of approximately $85-90 \mathrm{rpm}$. As can be seen from the Campbell plot, this will excite this mode at a frequency of $2 \mathrm{P}$. Figure 12 shows a plot of flapwise bending moment over 1 rotor revolution. The conditions for this

\footnotetext{
- " $\mathrm{nP}$ " means the mode oscillates $\mathrm{n}$ times per rotor revolution.
} 


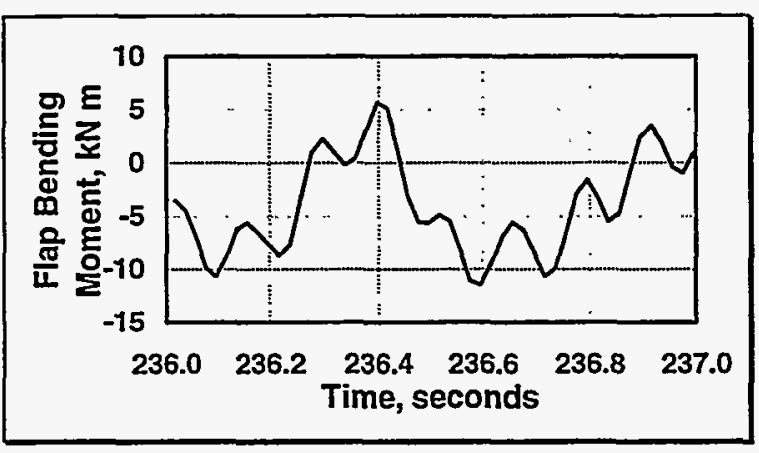

Figure 11. Blade-root flapwise bending moment showing 1 revolution with 8P harmonic content.

event were a wind speed of $13 \mathrm{~m} / \mathrm{s}$ and a rotation rate of $90 \mathrm{rpm}$. There is a large $2 \mathrm{P}$ harmonic content to this signal as well as a $6 \mathrm{P}$ harmonic content. The $6 \mathrm{P}$ content is due to the excitation of the second flap mode.

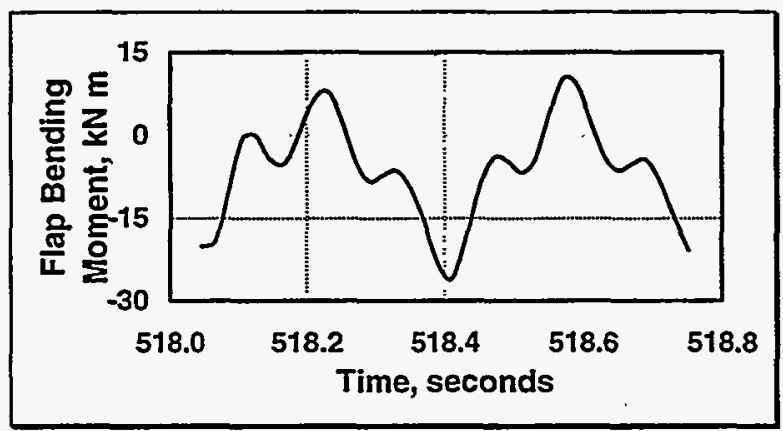

Figure 12. Blade root flapwise bending moment showing 1 revolution with $2 \mathrm{P}$ and $6 \mathrm{P}$ harmonic content.

We realize that much work remains in order to fully characterize these effects and to assess the impact of excitation of these system resonances on component fatigue life. We must study the excitation of the full system operational modes before we can fully assess the advantages or disadvantages of operating a VS machine.

\section{Conclusions}

We have incorporated a preliminary, simple, variablespeed control model into the FAST2 wind-turbine simulator. Due to the relatively fast execution time of the FAST2 code, we can perform simulations of long periods (10 minutes) of turbine operation and analyze results from a multitude of runs. We have begun a characterization of the loads and responses exhibited by a typical wind turbine undergoing variable-speed operation. We have made some preliminary comparisons of loads and responses between the VS machine and the FS machine having the same basic configuration.
We found that some of the extreme loads were lower for the VS machine than for the FS machine over the range of wind speeds we analyzed. The blade's flapwise bending moments had lower extreme values for the VS machine than for the FS machine. This effect was due to the lower rotor speeds of the VS machine at low wind speeds. At these low wind speeds, the blade's bending moments of the FS machine were more highly dominated by centrifugal effects than the VS machine, resulting in larger, negative (upwind) bending moments. These results depend a great deal on the rotor configuration, most notably the precone angle. For typical machines with nonzero precone angles, the PDs of blade root flapwise bending moments are taller and narrower for the VS machine than for the FS machine. These results could indicate some load-alleviating potential of the VS machine over the FS machine.

We also examined the rotor torque and found that the VS machine exhibited smaller extreme values for the cases we analyzed. This result was evident in the PDs, which were taller and narrower for the VS machine than for the FS machine for the wind speed cases that we analyzed. This result could indicate another load alleviating potential, especially for design of the turbine's drivetrain and gearbox.

One parameter that exhibited higher values for the VS machine was rotor teeter. Due to VS machine's lower rotor rotation speeds at low wind speeds, we saw that the teeter mode was more highly excited than for the FS machine. We must make further investigations into the effects of rotor speed upon teeter response.

We made a preliminary investigation of the rotor's symmetric flap modes at harmonics of the rotor speed. This is a very important consideration in deciding the rotor-speed range for the VS machine. Both the rotor's first and second symmetric flap modes responded strongly at certain rotor speeds. Much more work is needed to quantify this effect and to assess the impact of these trends on the turbine's fatigue life.

\section{FUTURE WORK}

We want to rainflow cycle count the data and feed the results into a fatigue-life code. This should give us an additional view of the impacts of variable-speed operation.

We plan to perform a similar study for three-bladed, rigid-hub turbines. We plan to implement more sophisticated control schemes in our simulation codes in order to model other variable-speed control systems, as well as to model blade aerodynamic control for limiting loads and power. 
We also plan to upgrade our methods for predicting a turbine's operational modal characteristics. To date we are only able to predict the modes of the full wind turbine system for nonrotating turbines. We need to be able to predict the full system operation modes, natural frequencies, and damping for various rotor speeds, including important coupling effects between components. Only then can we fully assess the impact of operating the VS machine at resonant natural frequencies.

\section{ACKNOWLEDGMENTS}

We thank Dr. R.E. Wilson and his team at Oregon State University for their careful formulation and development of the FAST codes. We also thank management at NREL and the U.S. Department of Energy (DOE) for encouraging us and for approving the time and tools we needed to perform this modeling and validation effort. This work has been supported by DOE under contract number DE-AC36-83CH10093.

\section{REFERENCES}

1. Elliott, A.S., and Wright, A.D. "ADAMS/WT: An Industry-Specific Interactive Modeling Interface for Wind Turbine Analysis." Wind Energy 1994, Edited by W.D. Musial, S.M. Hock, and D.E. Berg. SED-Vol. 14. New York: American Society of Mechanical Engineers; pp. 111-122, 2326 January 1994.

2. Wilson, R.E., Freeman, L.N., and Walker, S.N. "FAST2 Code Validation." Wind Energy-1995; January 29-February 1, 1995; Houston, Texas. New York: American Society of Mechanical Engineers; pp. 263-67.

3. Wilson, R.E., Freeman, L.N., Walker, S.N., and Harman, C.R. FAST Advanced Dynamics Code, Two-bladed Teetered Hub Version 2.4 User's Manual. Final Report. Golden, CO: National Renewable Energy Laboratory, March 1996. Work performed by Oregon State University, Corvallis, Oregon.

4. Hansen, A.C. Yaw Dynamics of Horizontal Axis Wind Turbines. NREL/TP-442-4822. Golden, CO: National Renewable Energy Laboratory, 1992. Work performed by the University of Utah, Salt Lake City, Utah.

5. Hansen, A.C. User's Guide to the Wind Turbine Dynamics Computer Programs YawDyn and AeroDyn for $A D A M S \circledR$, Version 9.6. Salt Lake City, UT: University of Utah, June 1996. Prepared for the National Renewable Energy Laboratory under Subcontract No. XAF-4-14076-02.
6. Muljadi, E., Butterfield, C.P., and Migliore, P. "Variable-speed Operation of Generators with Rotor-Speed Feedback In Wind Power Applications." Wind Energy, Energy Week, , PennWell Conferences and Exhibitions, Houston, Texas, ISBN 0-9648731-7-6, 1996,.January 29 to February 2,1996

7. Kelley, N.D. Full Vector (3-D) Inflow Simulation in Natural and Wind Farm Environments Using an Expanded Version of the SNLWIND (Veers') Turbulence Code. NREL/TP-442-5225. Golden, CO: National Renewable Energy Laboratory, 1992.

8. Veers, P.S Three-Dimensional Wind Simulation. SAND 88-0152. Albuquerque, NM: Sandia National Laboratories, 1988.

9. International Electrotechnical Commission Wind Turbine Generator Systems, Part 1: Safety Requirements, International Standard, IEC 1400-I, Second Edition, 1996-2, 1996.

10. Buhl, M.L., Jr. GPP User's Guide, A GeneralPurpose Postprocessor for Wind Turbine Data Analysis. NREL/TP-442-7111. Golden, CO: National Renewable Energy Laboratory, 1995.

11. Wright, A.D., Bir, G.S., and Butterfield, C.P. Guidelines for Reducing Dynamic Loads in TwoBladed Teetering-Hub Downwind Wind Turbines. NREL/TP-442-7812. Golden, CO: National Renewable Energy Laboratory, 1995. 